\title{
CREATIVITY IN TRANSLATOR TRAINING: BETWEEN THE POSSIBLE, THE IMPROBABLE AND THE (APPARENTLY) IMPOSSIBLE
}

\author{
LANCE HEWSON* \\ Faculty of Translation and Interpreting \\ University of Geneva
}

\begin{abstract}
The first part of this paper looks at how creativity has been explored in writings in the field of translation studies. It examines the stages in creative translation and investigates the creative process. The second part of the paper looks at how creativity can be exploited in the translation class by concentrating in particular on the liberating role of intralingual and interlingual paraphrase, while considering the various constraints operating on the selection of the optimal target text.
\end{abstract}

Keywords: conscious and semi-automatic translation, translation difficulties, intralingual and interlingual paraphrase, translational norms, translator training.

\section{Introduction}

Creativity is not a new subject in the field of translation studies. It has been widely explored as a theoretical concept, often in relation to language-pairspecific translation problems. Sometimes it is discussed in the context of literary translation, but more often its relevance is discussed in relation to pragmatic texts. Although few scholars addressed the subject in the early years of translation studies, ${ }^{1}$ a number of papers and full-length studies began to appear in the 1990s and 2000s, with the most prolific researcherboth in terms of his theoretical contribution and its practical applications-

\footnotetext{
Lance.Hewson@unige.ch

${ }^{1}$ Jiří Levý was one of the first scholars to give serious consideration to the subject, as can be seen in his Art of Translation ([1963] 2011), to which I refer below.
} 
being Paul Kussmaul. ${ }^{2}$ Yet despite the increasing attention given to the subject, it would be incorrect to believe that creativity is seen today as a key concept in translation studies. It is certainly of interest to scholars working on cognitive approaches, or those investigating translation processes ${ }^{3}$, but it is given no mention in many general works discussing translation theory. This, in a sense, is hardly surprising, as translation studies has gone through a period of exponential development, in particular with the series of "turns" that it has gone through in recent years, which, if nothing else, point to its interdisciplinary nature. ${ }^{4}$ Scholars working in the field of translator training are no exception to the rule: although some do indeed discuss the role of creativity in the translation classroom, others simply choose not to mention the phenomenon. ${ }^{5}$ It would also be fair to say that the situation prevailing in the translation classroom mirrors that of academic interest in the subject. While some translator trainers consistently encourage their students to creatively explore the potential of their mother tongue, others, probably a substantial majority, refer rarely to the concept, or simply do not speak of creativity in the classroom. ${ }^{6}$ In order to understand why this is so, and (hopefully) to remedy this situation, I shall use the first part of this article to give a brief overview of research on the subject, discussing what I believe to be shortcomings of current theoretical approaches. I shall also be revisiting some of the arguments I have put forward in earlier publications, and in a

${ }^{2}$ Kussmaul's publications are too numerous to quote here. A bibliography covering the period mentioned can be found in Bayer-Hohenwarter's article (2011) listed in the Works Cited section below.

${ }^{3}$ See, for example, Dancette et al. (2007), who use observation of translation processes to explore cognitive approaches to translating.

4 A summary of translation studies' different "turns" can be found in SnellHornby's (2010) article in the Benjamins Handbook of Translation Studies.

${ }^{5}$ This should not be taken as a criticism of the many excellent books and articles on the subject. It is understandable that for many scholars, creativity does not play a central role in the highly complex question of translator training.It is interesting to note that some of the researchers who have written on creativity do indeed explore how creativity can be used in the translation class-like, for example, Stefanink and Bălăcescu 2009, or Kussmaul 1995. It is instructive in this respect to consider the work of Michel Ballard. Despite having written specifically on the subject of creativity (1997), he merely refers in passing to creativity in his two works devoted to exploring translation problems (2003 and 2004).

6 The opinion I express here is the result of thediscussions and email exchanges I have had with colleagues at the University of Geneva's Faculty of Translation and Interpreting, and with colleagues teaching at other European universities. The results of the exchanges do not, of course, constitute an "objective” picture of the general situation in the translation class. 
forthcoming article on the subject. ${ }^{7}$ In the second part of the present paper, I shall turn my attention to translator training, and set out how creativity can be used by the trainer, to the greater benefit of the learner.

\section{Creativity in Translation}

\subsection{On creativity in general}

There is something paradoxical about the very notion of creative translating. A translator, after all, is not a "creator" in the same way as a writer who, in a naïve sense, creates "something" out of "nothing". The material that the translator works on is already there, so on one level there is nothing to be invented or conjured up. The key idea here, therefore, is reproduction and not production. This state of affairs explains why so many scholars have simply omitted to bring creativity into their discussions either of the translating process, or the product of that process, the translated text. The notable exception during the early years of what was to become the field of translation studies was Jiř́ Levý, who expressed frustration with the linguistic approaches that were prevalent in the 1960s, as they left out the key figure involved in producing the translation - the translator-and thus failed to take into account the importance of personality and the translator's "creative individuality" ([1963] 2001: 14). When researchers, and notably Paul Kussmaul, later began to explore the role of creativity in translation, the question arose of whether translation in general-all translation-can be called creative, or whether there are passages in source texts (corresponding to moments during the translation process) that call for a creative approach. In his 1991 article, Kussmaul foregrounds source texts showing a degree of singularity: "texts or passages where we cannot rely on linguistic norms and conventions, where set patterns, fixed collocations or typical idioms are not adequate when formulating the target text” (1991: 92). He adds: “... I think it is not unreasonable to suppose that texts which deviate from general linguistic norms and which in addition very often have a very complex structure [...] are especially suited to test the translator's creativity..." (ibidem). Later, in his book Kreatives Übersetzen $\left(2000^{\mathrm{a}}\right)$, he posits a more general theory of translator creativity: "The main aim of my book is to make us all aware of the fact that translating is a highly creative activity" $\left(2000^{\mathrm{a}}\right.$ : 16). ${ }^{8}$ Michel Ballard adopts a similarly generalizing viewpoint, underlining

${ }^{7}$ I am referring here to the two articles (2006 and 2012) mentioned in the Works Cited section below, and also to an article to be published in META in 2017, entitled "Les paradoxes de la créativité en traduction littéraire".

${ }^{8}$ The translations are my own, unless otherwise stated. I quote this and other examples in my article of 2006. 
that the simple fact of writing in another language presupposes resorting to shifts and transformations "which are part of an act of creation that happens in another linguistic fabric" (1997: 86, translated). Such a conception of creativity naturally leads one to the question of how creativity can be taught, and it was once again Kussmaul (1995) who was the pioneer here. But before looking at this crucial question, it is important to note, firstly, that not all scholars have gone down the all-translating-is-creative path, and secondly, that much of the research which has been "borrowed" from other disciplines is not always directly applicable to translation studies.

Some scholars do not take the view that translating is necessarilyor always-a creative operation. Here we need to turn once again to Jiří Levý, who spoke not only of the translator's creative individuality, but also drew a distinction between "creative" and "mechanical" translators. The former are "able to imagine the realities they are expressing, reaching beyond the text to identify the characters, situations and ideas that lie behind it, whereas non-creative translators merely perceive the text mechanically and merely translate the words" ([1963] 2011: 34). This clear-cut, and indeed categorical distinction has been nuanced by other researchers such as Bălăcescu and Stefanink (2003 $)$ or Englund Dimitrova (2005). The former note that competent translations rely on a stock of ready elements that are marked in both situational and cultural terms and that are "almost automatically" introduced into the target text $\left(2003^{\mathrm{a}}: 131\right)^{9}$, whereas the latter makes a distinction between "automatic processing" and problem solving (2005: 26). In my forthcoming paper mentioned in footnote 7 I try to build on Levýs distinction, not by opposing two different types of translators, but by noting how when analysing translated texts, one can show that some translational choices appear to be predictable, whereas others are surprising or unexpected. For the former, I argue, the translator simply-or mechanically, semi-automatically_introduces the solution that he or she immediately knows to be correct, whereas the latter requires conscious-and therefore creative-manipulation of the target language. I shall be returning to this distinction below.

I shall now turn my attention to the ways in which translational creativity is approached in the literature, starting from the general consensus that a strict definition of the concept of creativity is not really possibly (Bayer-Hohenwarter 2011: 664). My major source here is the various writings of Kussmaul (i.e. 2000' ${ }^{\mathrm{a}}$ :20), who points to three key stages in

${ }^{9}$ They speak in French of "préformés linguistiques situationnels, marqués culturellement, que le bon traducteur bilingue et bi-culturel doit avoir à sa disposition et placer de façon quasi automatique dans le discours de la langue cible". 
creative translation: (i) the existence of a translation problem, which, in the hands of the translator, is (ii) solved by something "new", with this result being (iii) approved by an expert.

\subsection{The stages in creative translation}

For many scholars, the starting point of the creative process is the identification of a problem. What is important here is not so much the nature of the problem - as translators know too well, problems may be legion-but, as Mathilde Fontanet (2005: 433) explains, the fact that the translator is incapable of spontaneously finding an equivalent in the target language. This is, of course, a valid point, and much space has been devoted to the discussion of specific problems and their potential (creative) solutions (Hewson 2012). Moreover, it dovetails nicely with the distinction made above between conscious manipulation of the target language and semiautomatic translational choices that the translator knows to be correct-the latter being used when there is no translation problem to be solved. There are, however, two difficulties here. The first concerns the nature of the solution that the translator will put forward. There is simply no guarantee that a period of conscious reflection will necessarily produce a creative translation. It is to be hoped that the professional will strive to produce a correct solution, but an expert may not judge it to be really creative, as I shall show when discussing a translation of one of Simenon's Maigret stories. The second difficulty here is of particular interest to the translator trainer: by limiting the inspiration behind creative translating to the existence of some kind of problem one is presupposing that there can be no creative translating per se, in other words that the translator needs to be confronted by a problem for the creative process to begin. I would, however, argue that almost any source-text fragment can (potentially) be used to produce a creative translation. This can perhaps best by envisaged by considering the late revision stages of translating. At this point, the translator concentrates in particular on the overall "feel" of the target-text-in-the-making, and thus on the prosodic elements. He or she might decide that the form initially chosen, although quite adequate in terms of the way it expresses the translator's interpretation of the source text, does not read sufficiently well. The translator will paraphrase and rewrite until satisfied with the new version. The result is different, and sometimes substantially different, from the initial version. The creative elements do not stem from the identification of a problem (I am assuming here that the initial version would have been acceptable), but result from the translator's desire to go beyond the fairly standard form adopted during the preliminary draft of the target text. 
I now turn my attention to the two other stages identified by Kussmaul: producing something new in the translation, which then needs to be validated by an expert.

In his 1991 article quoted above and in his book on training the translator (1995), Kussmaul emphasises that for a translation to be considered as creative, it must be "new" or "novel". The key question that one must ask here is: new or novel in relation to what? The answer cannot be the source text per se (unless, of course, one subscribes to the all-translatingis-creative hypothesis). But one can compare a published translation with the expected or predictable outcomes that can be constructed on the basis of the usual linguistic forms commonly produced in the target language.The potentially creative solution is one that is at variance with those usual linguistic forms, and it remains potentially creative until validated (or not) by the expert. Before looking at some examples, it is interesting to reflect on the rationale lying behind such an approach. It presupposes that translators tend to treat linguistic input in predictable ways. This is partly because translation practice confirms again and again that certain solutions are the right ones, and partly because, as Hermans (1991) has underlined, translation is essentially a norm-based activity, with the translator experimenting first of all with standard solutions. Bilingual dictionaries provide normative translation solutions for lexical items, which are incorporated into standard syntactic patterns and governed by "correct" grammatical usage. The normative solutions can then be fine-tuned by considering the framework in which the translation takes place (including the perceived needs of the readers or listeners, the type of communication channel and the function of the target text, if relevant). Either a normative solution will be adopted, or the translator will look further afield.

I shall examine two examples to see how the new/novel criterion can be made to work. The first involves the message flashed up on French motorways in bad weather: "La météo varie, votre vitesse aussi". Out of context, a predictable translation might read "Weather changes, your speed (should) too", with a number of other possible forms, including "weather forecast" for "météo", "varies" for "varie", "so does your speed" for "votre vitesse aussi", and so on. If the aim were to make the signs on French motorways bilingual (thus keeping the same function in the two languages), then the pragmatic markers involved would cause the translator to reject the possibilities just mentioned, as in French they rely on a communication strategy based on an implicit message which, from the point of view of English, is not sufficiently direct. An explicit (and unambiguous) translation - which is creative because linguistically unpredictable-would read: "Slow down", or more explicitly: "Rain, slow down". If the expert consulted decides that the choice is appropriate (the key criterion in this case 
would be the function of the target text), then he or she can validate this as creative translation.

My second example comes from the published translation of one of Simenon's Maigret books. ${ }^{10}$ As is often the case in these stories, Maigret has a rather tense relationship with the examining magistrate overseeing the case he is working on. In this story we read: "Deux ou trois fois, la veille, le juge Coméliau avait téléphoné à son bureau” (2012: 77). The predictable translation one can imagine here may read: "Two or three times on the previous day, Judge Coméliau had phoned his office", with a number of possible variations including the positioning of the two adverbial groups. The published translation reads: "By the time he had got back to his office the previous evening, there were several messages on his pad requesting him to ring Judge Coméliau" (1971: 220). What is interesting here is that the reader of the translation is given the opportunity of learning details which are simply not present in the original, and which, moreover, cannot be inferred from what we do read. There is no evidence in the French (here or elsewhere) that Maigret actually went back to his office on the day in question. There is also no mention of there being a pad on his desk, or that his inspectors are in the habit of leaving him messages on such a pad. So what we have here is a series of additions. But do they count as creativity? The role of the expert is clearly very important, and what does seem clear is that one needs to adopt a macro-level perspective in order to be able to judge the appropriate nature of such modifications - be they additions, explicitations, implicitations or omissions. I argue in my forthcoming article that the modifications here alter our perception of the hero and of the way in which he works. Bearing that in mind, it is fair to judge that these additions cannot be classified as creative translational choices.

\subsection{The creative process}

Having looked briefly at the stages of creative translating, I would like to review how different scholars have addressed the question of the creative process. In his earlier work, Kussmaul borrowed from research in psychology by using the four-phase model taken from the writings of Wallas (1926). ${ }^{11}$. The four phases are "preparation, "incubation", "illumination" and "evaluation” (Kussmaul 1991: 93). However, Kussmaul was clearly unhappy with his descriptive model (he noted how hard it is to distinguish between incubation, illumination and evaluation), and in his article entitled "Types of

\footnotetext{
${ }^{10}$ I use the same example in my forthcoming article mentioned in footnote 7.

${ }^{11}$ Graham Wallas, The Art of Thought. New York: Harcourt Brace, 1926. Print. Fontanet (2005) gives a detailed historical overview of the research.
} 
creative translating" $\left(2000^{b}\right)$, he combines insights from Langacker's cognitive grammar ${ }^{12}$ with Fillmore's writings on "scenes" and "frames" ${ }^{13}$ to come up with five different types of creative translating. The first of these is called the "chaining of categories", which is used to explain creative translations that use what are, on the face of it, different semantic categories, but where the link between these different categories becomes apparent when they are seen to be part of larger scenarios. The translation is therefore based on a change of focus, which, later in the article, Kussmaul calls "moving from frame to frame" $\left(2000^{\mathrm{b}}\right.$ : 125$)$. The second type is called "picking out scene elements within a frame" (later paraphrased as "moving from frame to scene"). Kussmaul stresses the importance of "imaginative reading" $\left(2000^{\mathrm{b}}: 122\right)$, which involves verbalising what is understood in the source text. He explains that we focus on "one particular element of the scene, which may be said to stick out as the figure against the ground of the rest of the scene" (ibidem, italics in the original). The third type involves "enlarging a scene", in other words adding a new aspect to the source scene. This (rather confusingly) is later called "moving from scene to scene". The fourth type is called "framing a scene", described by Kussmaul as "zoom[ing] out, as it were, until we reach the frame so that the whole scene is in the picture" $\left(2000^{\mathrm{b}}: 124\right)$. The fifth and final type involves "thinking up a new frame”. Kussmaul concludes by saying:

no matter what we do, the processes which inspire creative solutions are always linked with scenic visualisations. This opens up the way for changing the focus in order to pick out elements in the scene or including them all. Scenic visualisations thus contribute to the novelty of a translation and help make it a creative product. $\left(2000^{\mathrm{b}}\right.$ : 126 , italics in the original)

Other scholars, such as Bălăcescu and Stefanink $\left(2003^{b}\right)$ or Dancette et al. (2007), also turn to cognitive linguistics with the aim both of describing and explaining creative solutions, and ensuring that there is a sufficiently robust theoretical model available for translation scholars to use. Like Kussmaul, Bălăcescu and Stefanink are also concerned with the practical applicability of theoretical models in terms of translation practice. However, if one adopts the double perspective of teaching creativity and practising creativity in one's own translations, one rapidly comes to the conclusion that the current models are little more than interesting hypotheses which are difficult to confirm, and which do not necessarily stand up to the

${ }^{12}$ Ronald W. Langacker, Foundations of Cognitive Grammar. Stanford: Stanford University Press, 1987. Print.

${ }^{13}$ Charles J. Fillmore, "Scenes-and-Frames Semantics". Linguistic Structures Processing. Ed. Antonio Zampolli. Amsterdam: North Holland, 1977. 55-88. Print. 
test of practice. The long quote from Kussmaul above is a case in point. The first sentence is prescriptive ("are always linked..."), thereby confining practice to one particular vision of what "happens" when translators manifest creativity. But why rule out so definitively other ways of proceeding? Other translation scholars describe their own way of working in very different terms. Mathilde Fontanet (2005), for example, paints a complex picture of the kinds of activities she engages in (which she organises by means of the first two phases in the four-phase model (preparation and incubation)). During the former stage, she mentions such activities as "searching tentatively and uncertainly", or "thinking about the historic context", or "identifying the formal or semantic relationships between the words of the source text” (2005: 438, translated) ${ }^{14}$. Among the activities identified during the incubation phase, she mentions how she might switch her attention to other problems or simultaneously address different issues ${ }^{15}$.I would add here that scenic visualisations are not (usually) part of my own practice, which may involve very different types of activity. The most common of these is to work on linguistic associations that play out in a back-and-forth paraphrastic movement between the two languages. Like other translators, I also store away questions, knowing by experience that unexpected answers might suggest themselves at a later time. Finally, an imaginative rewriting may occur during the revision process.

I would conclude this section on a note of caution. It seems to me that translation scholars are very dependent on research carried out in other fields, and that this research has not been sufficiently rethought to be entirely relevant in what is, after all, a unique situation-where one rewrites an already existing message using a new linguistic and cultural system. Moreover, it is difficult to carry over such research into the translation classroom where, once again, students are required carry out a unique type of exercise. My third section, which looks at the potential and role of creativity in translator training, attempts to address these shortcomings.

\footnotetext{
${ }^{14}$ In the original: "Selon moi, la phase de préparation comprend des démarches aussi diverses que le tâtonnement, la réflexion sur le contexte historique, le repérage des rapports formels ou sémantiques entre les mots du texte de départ, la consultation de dictionnaires ou d'autres ouvrages, la traduction provisoire, les interrogations, les paraphrases et les associations conscientes."

${ }^{15}$ She describes the whole of the incubation phase as follows: "La phase d'incubation fait intervenir, entre autres, la temporisation, l'inscription de plusieurs solutions, les changements de perspective (mouvement pendulaire ou cyclique), la concentration sur d'autres problèmes, l'alternance entre considérations sémantiques et syntaxiques et les interrogations simultanées.”
} 


\section{Creativity in Translator Training 3.1 Defining translator training}

I shall begin this section by clarifying what I mean by translator training. I am referring here to classes that are designed to train future professional translators, working out of their passive (i.e. acquired) languages and into their active language (i.e. mother tongue). I am therefore explicitly excluding the training of translators who will work out of their mother tongue and into their passive language(s). This is partly because, in my view, trainee translators are only able to develop total confidence in their active use of the mother tongue as the target language, and partly because creativity requires two particular competences, both of which can be most efficiently developed in the mother tongue. The first of these is the ability to explore the richness of the language, and the second is the capacity to make informed decisions about the most relevant of the potential translational choices that have been found. The vast majority of students translating into their passive languages do not have a sufficiently broad knowledge of those languages, and lack the sensitivity which is needed to choose between rival versions of the target text. ${ }^{16}$ It also follows that I am specifically excluding translation classes whose aim is to boost learners' (passive) language abilities, and classes that are aimed at a specific types of student (such as those taking the competitive teaching examinations in France). But even with these provisos, it is not easy to make general statements about teaching strategies that can be used in translator training. I am speaking here from the particular perspective of teaching translation into English, but some of the difficulties experienced are relevant to all translation students-at least those using European languages. With languages that are widely spoken, there is the problem of which standard to adopt (British versus American English, for example). There is also the more general difficulty associated with the heterogeneous nature of student intake-my experience is that in the same classroom I will find mature students with broad experience in a specialised field and/or with writing experience, and students who have just completed their Bachelor's degrees, and thus have little or no experience of a work environment (or, indeed, of sustained writing in English). What follows, therefore, is aimed at a hypothetical middle ground occupied by average students of translation.

It is useful to conclude this opening section by stressing that creativity in the translation class is not some universal panacea. However, it

${ }^{16}$ In Hewson 2013 I present more detailed arguments explaining what I believe to be the pitfalls of translating into a passive language. Other scholars, such as Nike Pokorn (2005), argue in favour of the opposite point of view. 
does help students to address a number of the difficulties that the greater majority of them habitually experience. I shall look at typical difficulites in some detail, and then explain why it is I believe that exercises in creativity help students to overcome them.

\subsection{A brief catalogue of difficulties}

The first difficulty met by trainee translators concerns the way that they read and interpret the source text. I am assuming that students accepted on training programmes will have a reasonable level in their passive language(s), so I am not considering trainees who are simply not capable of identifying standard source-text forms or interpreting what they mean. What concerns me, then, is awareness of the importance of specific elements in the source text, and in particular (i) recognising culturally specific references, and (ii) developing sensitivity to nuances of meaning. As we shall see below, a creative orientation in reading the source text can be of considerable help in such cases.

The second difficulty results from the hypnotic effect that the source text exercises on the learner translator. This, characteristically, is reported by students who have little experience of translating. They are put in front of a source text in all its singularity and asked to recreate this text in their mother tongue. The source text, from their point of view, is there in front of them in black and white, and it is (as it were) everything - they discover that all they have is a blank sheet of paper, or, of course, a cursor flashing on a wordprocessing programme showing a word-count of zero. The very form of the source text seems to represent a kind of perfection which, later perhaps, will inspire them, but at this early stage paralyses them.

The third difficulty stems from the received ideas that people"ordinary" people who are not professional translators-have about translation. There are received ideas both about the translation process (what happens when one translates and therefore how one "should" translate) and the product (what a translation should look like, in particular in comparison to the original). Just how important such ideas are has been underlined by Andrew Chesterman (1997), who goes so far as to identify a translation norm-the "expectancy" norm-based on readers' expectations concerning translated texts. One can, of course, argue about the strength of such a norm and question how, for a particular translation, readers' expectations can be identified. But even without specific information, it is helpful to work with received ideas about translation, and in particular the one that says that a translation should look like its original, meaning that when one puts source and target texts side by side, there is virtually a one-to-one correspondence between the two, with nothing added and nothing removed. Such a 
perception may weigh on trainee translators, in that they unconsciously adopt strategies that facilitate this type of result, with the default strategy being some form of literal translation-described by Chesterman (1997:94) as "maximally close to the S[ource]L[anguage] form, but nevertheless grammatical". This narrow view both of the process and the product weighs heavily on the way that learner translators approach their translation work, and encourages them to produce stilted prose in their mother tongue, which they justify by saying that that is what the original "says". In short: this difficulty comes from the propensity to produce some kind of literal translation, in the more or less conscious belief that it is optimally equivalent to the source text.

The fourth and final difficulty concerns more generally the way that the trainee translators express themselves in their mother tongue. This difficulty is clearly implicitly present in the three situations described above, but takes on a particular form when there is a need to find a specific "voice" in the target language—-necessitating (once again) a creative approach.

\subsection{The role of creativity}

I shall begin this section by giving a brief definition of creativity in the translation classroom. Creativity in this context is the ability to exploit the resources of both source and target languages in order to produce unpredictable micro-level translation solutions that are coherent with the macro-level interpretation given to the text and compatible with external parameters. I shall comment on the various parts of this definition by coming back to the different difficulties outlined in section 3.2 above.

Perhaps the most surprising part of the definition given above is the mention of the ability to exploit the resources of both source and target languages. One might wonder why one needs to exploit the source language when the source text is already available in its definitive form. The reason behind this idea stems from the first difficulty mentioned abovedeveloping sensitivity to nuances of expression in the original text. ${ }^{17}$ When students are introduced to the idea of intralingual paraphrase applied to the source text, they begin to understand in concrete terms how meaning is generated by difference, and how nuance of meaning can be observed by considering paraphrases of the original text. Put another way, by looking at what the author of the source text chose not to say, one can better appreciate and interpret what he or she actually did say. I shall illustrate this by looking

${ }^{17}$ I do not address the other difficulty mentioned at the beginning of section 3.2 (recognising culturally specific references), as this requires a specific type of training that has no link with creativity. 
at the first sentence of Maupassant's story "La Maison Tellier": "On allait là, chaque soir, vers onze heures, comme au café, simplement”. ${ }^{18}$ Even a cursory glance at the sentence is enough to know that the translator is faced with problems of interpretation, style and narrative voice. The very first word, the pronoun "on", opens up an interpretative problem, particularly when we read that the second sentence (beginning a new paragraph) begins with "ils" before reverting back to "on". Who is referred to, and what is the status of the narrator? Where the people obliquely mentioned in the sentence actually go is left vague ("là"), as is their manner of going ("comme au café", "simplement"). We note the five juxtaposed groups making up the sentence and hear a measured, rhythmic narrative voice, laying down point by point the framework for the story. Almost any type of paraphrase ${ }^{19}$, apart from the simplest syntactic rewrite, will force the translator to explicate or analyse: in so doing, he or she will necessarily explore interpretative possibilities. A few such possibilities would be:

1. Cela se passait chaque soir vers onze heures. Les habitués entraient dans le lupanar sans cérémonie, comme dans un établissement quelconque.

2. Tous les soirs, vers les 11 heures, cela allait de soi: les hommes se rendaient à la maison de tolérance-une sortie comme une autre.

3. Les clients de la maison close avaient l'habitude de s'y présenter tous les soirs vers onze heures, sans protocole particulier, un peu comme ils se seraient rendus au café. ${ }^{20}$

What these paraphrases show us is that the original text is extraordinarily elliptical. Where Maupassant is not explicit, the paraphrases tell us something: about the subject "on", where it is precisely that they go, and the atmosphere surrounding this habitual action. We also see how paraphrases 1 and 2 seriously modify the narrative voice (using respectively two sentences and one sentence with two major pauses, producing a blurred effect of rhythm). And we may also begin to think about ways of translating expressions, such as "simplement", that do not spontaneously trigger target language solutions. ${ }^{21}$ The three explicative variations ("sans cérémonie",

\footnotetext{
${ }^{18}$ Maupassant [1881] 1974: 256. This is one of the examples I use in Hewson 2016 to illustrate the difficulties of interpretation and the role of uncertainty in the translation process.

${ }^{19}$ See Hewson 1999 for a typology of potential paraphrases that can be used when rewriting a source text.

${ }^{20}$ I would like to thank Mathilde Fontanet for her suggestions.

${ }^{21}$ I suggested above that scholars working on creativity concentrate on translation problems, to the detriment of passages that present no apparent difficulties. But a
} 
"cela allait de soi" and "sans protocole particulier") will stimulate creative possibilities in the target language (one might think of "with no particular ceremony"). Paraphrasing in a foreign language is no easy task, and I am not trying to suggest that trainee translators would immediately be capable of coming up with useful variations of a particular source-text sentence. What I am suggesting, though, is that the translation trainer has an opportunity to help students learn how to free a source text from the rigid, textual form in which it is presented and to see it in a more creative light by envisaging other ways that the author could have chosen to write.

The other difficulties outlined above dealt with the hypnotic effect of the source text, received ideas about the form that the target text should take and the limited means of expression that trainees often manifest when writing in the mother tongue. It will already be clear that the technique of intralingual paraphrase described above will help to weaken the "grip" that the source text exercises on the translator. But as mentioned above, learning how to paraphrase in the foreign language is not easy, and trainee translators may first be more at ease with the idea of exploring variation in their mother tongue. They can be encouraged to practise rewriting by exploiting both lexical and syntactic variations of the developing target text, and by coming up with series of possible translational choices. However, there remains the difficulty of choosing between the different target-language possibilities. This is why the definition given above contains the double proviso of coherence with the macro-level interpretation and compatibility with external parameters. The former requires trainees to look at the wider patterns that, in their view, need to be given special attention-for example, terms that take on a symbolic importance or the use of stylistic devices. The latter introduces external, ad hoc parameters that affect a particular translation order-such as constraints imposed by the initiator or norms associated with the type of publication.

A final point should be made about the use of creativity in the translation classroom. It can be salutary to loosen the normal safeguards that accompany any exercise in translation, and that stipulate that the result must correspond to a predefined yardstick of accuracy or conformity. Here we meet one of the great difficulties of teaching translation: the teacher works with an internalised set of criteria that the learner has the right to knowpartly as these criteria will be used when the learner's competences are tested. But when it comes to verbalising the criteria, teachers are often at a loss, and come up with rather empty terms such as "faithfulness" or "equivalence". Now there must, of course, be a yardstick, and I would

creative approach is also very helpful when the translator is indeed faced with problems, such as translating "simplement” into English! 
suggest encouraging students to work on producing a target text whose interpretation is in line with the salient interpretative characteristics of the source text. However, before emphasising the controlling function of such criteria, it is helpful for the teacher to develop a bolder and less constrained approach, allowing for a richer use of the target language's creative potential. I am referring here to the "improbable" and "apparently impossible" mentioned in the title of this paper in the belief that the more the learner is stimulated into seeing different and genuinely unpredictable possibilities, the more inventive and fluent a translator he or she will eventually become. It is only after this first stage has been fully exploitedwhen students have had the opportunity of developing their creative writing skills - that it becomes necessary to introduce selection criteria in order to turn students into efficient translators.

\section{Conclusion}

I mentioned above that many translation scholars do not address the question of creativity in translation in general, and in the translation class in particular. One of the reasons for this state of affairs is the perception that there are types of translating that simply do not require creativity. And all translators have dealt with texts where there appears to be simply no room for anything beyond a standard transfer between source and target languages. I am thinking here of official documents such as birth certificates, or instructions for using electronic devices. A free-lance translator, however, will meet challenging texts belonging to a host of fields that will certainly benefit from the kind of creative approach outlined above. The professional translator generally knows where the limits to translating lie, and hence will not need to push creativity beyond a certain point. Trainees, however, begin their learning path with all sorts of misconceptions, and little experience in exploiting the possibilities offered by the mother tongue. It could thus be argued that at least one part of a training programme should be given over to exercises that encourage trainees to search for solutions that might even appear to be outrageous. And if they are outrageous then so much the better, as this is an indication of increasing confidence in using language. Naturally enough, as a course progresses, more and more criteria can be introduced to help the learner to choose between potential choices. By the end of a course, students will become efficient both at producing a wide range of possibilities, and homing in on the most relevant choice. If the seeds of creative translating have been sown, then the students-who meanwhile have become professionals-will remain alert to the dangers of semiautomatic or mechanical translating and will always be ready to look beyond 
standard solutions to improve the final product that they submit to their employers.

\section{Works Cited}

Bălăcescu, Iona and Stefanink, Bernd. "Du structuralisme au cognitivisme : la créativité au fil des théories de la traduction.”Le langage et l'homme 38.1 $\left(2003^{\mathrm{a}}\right): 125-143$. Print.

Bălăcescu, Iona and Stefanink, Bernd. "Modèles explicatifs de la créativité en traduction.”Meta48.4 (2003 $\left.{ }^{\mathrm{b}}\right)$ : 509-525. Print.

Ballard, Michel. “Créativité et traduction.”Target 9.1 (1997): 85-110. Print.

Ballard, Michel. Versus : la version réfléchie. Repérages et paramètres. Paris: Ophrys, 2003. Print.

Ballard, Michel. Versus : la version réfléchie. Des signes au texte. Paris: Ophrys, 2004. Print.

Bayer-Hohenwarter, Gerrit. “'Creative Shifts' as a Means of Measuring and Promoting Translational Creativity."Meta 56.3 (2011): 663-692. Print.

Chesterman, Andrew.Memes of Translation: the spread of ideas in translation theory. Amsterdam: John Benjamins Publishing Company, 1997. Print.

Dancette, Jeanne, Audet, Louise and Jay-Rayon, Florence. "Axes et critères de la créativité en traduction.” Meta 52.1 (2007):108-122. Print.

Englund Dimitrova, Birgitta. Expertise and Explicitation in the Translation Process. Amsterdam: John Benjamins Publishing Company, 2005. Print.

Fontanet, Mathilde. “Temps de créativité en traduction.”Meta 50.2 (2005): 432-447. Print.

Hermans, Theo. “Translational Norms and Correct Translation.”Translation Studies: The State of the Art. Ed. Kitty van Leuven-Zwart and Ton Naaijkens. Amsterdam: Rodopi, 1991. 155-69. Print.

Hewson, Lance. "A propos de la paraphrase dans le cours de traduction."Les Cahiers de l'ILCE 1 (1999): 51-68. Print.

---. "The Vexed Question of Creativity in Translation."Palimpsestes hors série (2006):53-63. Print.

---. “Traduire: les limites de la créativité.” Les mouvements de la traduction. Ed. Annick Ettlin and Fabien Pillet. Geneva: MétisPresses, 2012. 113-128. Print.

---. "Is English as a Lingua Franca Translation's Defining Moment?” The Interpreter and Translator Trainer 7.2 (2013): 257-77. Print.

---. $\quad$ "Les incertitudes du traduire.”Meta 61.1 (2016): 12-28. Print.

Kussmaul, Paul. "Creativity in the Translation Process: Empirical Approaches.”Translation Studies: The State of the Art. Ed. Kitty van LeuvenZwart and Ton Naaijkens. Amsterdam: Rodopi, 1991. 91-101. Print.

---. Training the Translator. Amsterdam: John Benjamins, 1995. Print.

---. $\quad$ Kreatives Übersetzen. Tübingen: Stauffenburg Verlag, 2000'. Print.

---. “Types of creative translating." Translation in Context. Ed. Andrew Chesterman, Natividad Gallardo San Salvador and Yves Gambier. Amsterdam: John Benjamins Publishing Company, 2000․ 117-126. Print. 
Levý, Jiří.The Art of Translation. Transl. Patrick Corness. Amsterdam: John Benjamins Publishing Company, ([1963] 2011). Print.

Maupassant, Guy de. "La Maison Tellier.”Contes et Nouvelles 1. Paris: Gallimard, [1881] 1974. 256-283. Print.

Pokorn, Nike K. Challenging the Traditional Axioms. Amsterdam: John Benjamins, 2005. Print.

Simenon, Georges. Maigret et le corps sans tête. Paris: Omnibus, [1955] 2012. Ebook.

---. $\quad$ Maigret and the Headless Corpse. Transl. Ellen Ellenbogen.Fourth Omnibus. Harmondsworth: Penguin, 1971. 169-205. Print.

Snell-Hornby, Mary. “The turns of Translation Studies.”Handbook of Translation Studies 1 (2010): 366-370. Print.

Stefanink, Bernd and Bălăcescu, Iona. "Traduction professionnelle - traduction pédagogique : même combat!’Traductologie et enseignement de traduction à l'Université. Ed. Michel Ballard. Arras: Artois Presses Université, 2009. Print. 